\title{
$433 \mathrm{MHz}$ TPMS용 직각 스파이럴 구조 안테나 설계 및 제작
}

\section{Design and Fabrication of a Rectangular Spiral Type Antenna for $433 \mathrm{MHz}$}

\author{
오 승 곤 · 안 준 오* 김 부 균 ${ }^{* *}$ \\ Sung-Kon Oh $\cdot$ Juno An* $\cdot$ Boo-Gyoun Kim** \\ 요 약
}

본 논문은 타이어 휠로 인한 전파의 감쇄를 최소화하기 위해 직각 스파이럴 형태의 TPMS용 송신 안테나를 설계하고 제작하였다. 설계된 안테나의 $433 \mathrm{MHz}$ 주파수에서의 $S_{11}$ 은 시뮬레이션 결과, $-10 \mathrm{~dB}$ 대역폭이 23 $\mathrm{MHz}(427 \sim 450 \mathrm{MHz})$ 가 확보되었으며, 설계된 안테나를 두께 $0.3 \mathrm{~mm}$ 인 황동 재질로 $5 \mathrm{~mm}(W) \times 23 \mathrm{~mm}(D) \times 10$ $\mathrm{mm}(H)$ 의 크기로 제작한 후 반사 손실을 측정한 결과, $-10 \mathrm{~dB}$ 대역폭이 $433 \mathrm{MHz} \pm 10 \mathrm{MHz}$ 로 충분한 대역폭이 확보됨을 확인하였다. 제작된 안테나의 방사 전력은 휠에 미부착시 $-44.21 \mathrm{dBm}$, 휠에 장착 시 $-50.0 \mathrm{dBm}$ 으로 측정되었으며, 실제 데이터 송수신 테스트를 통해 실용화가 가능함을 확인할 수 있었다.

\section{Abstract}

In this paper, the rectangular spiral shaped antenna is designed and fabricated for $433 \mathrm{MHz}$ TPMS. Proposed antenna has the $-10 \mathrm{~dB}$ impedance bandwidth of $23 \mathrm{MHz}(427 \sim 450 \mathrm{MHz})$. The antenna is fabricated with the size of $5 \mathrm{~mm}$ $(W) \times 23 \mathrm{~mm}(D) \times 10 \mathrm{~mm}(H)$ by brass material. Return loss is below $-10 \mathrm{~dB}$ at $433 \mathrm{MHz} \pm 10 \mathrm{MHz}$ mounted tire wheel and not mounted both. The radiation power is $-44.21 \mathrm{dBm}$ without wheel and $-50.0 \mathrm{dBm}$ installed wheel. The proposed antenna can be practical use through data transmission test results.

Key words : TPMS, Rectagular Sprial Antenna, Small Antenna, Vehicle Wheel

\section{I. 서 론}

타이어 압력 모니터링 시스템(TPMS: Tire Pressure Monitoring System)은 차량의 타이어 내부에 설치된 압력 센서로 타이어 공기압을 감지하여, 이를 운전 자가 확인할 수 있도록 하여 차량의 안전사고를 방 지하는 차량 안전 보조 시스템이다. 미국에서는 타 이어 결함으로 인한 전복 사고를 계기로 2000년 TREAD Act(Transportation Recall Enhancement, Acco- untability and Documentation Act)를 제정하여 미국 내 생산 차량에 $\mathrm{TPMS}$ 를 점진적으로 장착하도록 권 고하고, 2007년 9월 이후부터는 미국 내 전 차량에 $\mathrm{TPMS}$ 를 장착토록 의무화하였다 ${ }^{[1]}$. 우리나라의 경우 에도 2011년 3월 국토해양부에서 $\mathrm{ESC}$ 와 TPMS 장착 의무화 및 LED 광원 사용 허가를 골자로 한 자동차 안전기준에 관한 규칙 개정안을 발표하여 2013년 1 월 1 일 이후부터 모든 신규 승용차 및 3.5 톤 이하 승 합화물 특수차에 TPMS를 의무 장착토록 규제하고

\footnotetext{
숭실대학교 전자공학과(Department of Electronic Engineering, Soongsil University)

*미래전파공학연구소(Institute for Future Radio Engineering)

**숭실대학교 정보통신전자공학부(Department of Information Technology \& Electronic Engineering, Soongsil University)

• Manuscript received April 4, 2012 ; Revised May 2, 2012 ; Accepted May 11, 2012. (ID No. 20120404-036)

· Corresponding Author : Juno An (e-mail : juno@ifre.re.kr)
} 
있다.

이를 위해 방송통신위원회는 TPMS 용도의 주파 수로 $433 \mathrm{MHz}$ 대역 $(433.795 \sim 434.045 \mathrm{MHz}$, 점유주 파수대폭 $250 \mathrm{kHz}$ 이하)을 데이터 전송용 특정소출 력 무선기기로 2005년 12월 분배한 바 있다.

TPMS 시스템은 크게 타이어 휠에 장착되는 송신 부와 운전석에서 이를 모니터링 하는 수신부로 구성 되며, 신호의 송수신은 전파를 통하여 이루어진다 ${ }^{[2]}$.

수신부용 안테나는 차량의 운전석 부근에 설치되 어 안테나의 크기나 기타 외부적인 환경의 제약이 덜하지만, 송신부용 안테나의 경우 압력 센서의 신 호를 수신부로 송신할 때 금속으로 이루어진 타이어 휠로 인한 전파 감쇄를 최소화하고, 공간적인 제약 을 극복할 수 있는 소형화된 구조의 안테나 설계와 제작이 필수적이다 ${ }^{[3]}$. 기존에 분석되었던 Loop ty$\mathrm{pe}^{[4]}$, Printed Monopole type ${ }^{[5]}$, PIFA type ${ }^{[6]}$ 등은 안테 나의 방사효율이 낮거나, 물리적인 크기에 의해 적 용하기가 힘든 문제점이 있었다.

따라서 본 논문에서는 타이어 휠로 인한 전파 감 쇄를 최소화하고 송신모듈 내부 공간에 장착이 가능 하도록 소형화된 크기의 직각 스파이럴(rectangular spiral) 형태 TPMS용 송신 안테나를 설계하고, 이를 제작하여 성능을 검증하였다.

\section{II. $433 \mathrm{MHz}$ TPMS용 직각 스파이럴 형태 송신 안테나 설계}

TPMS 송신 안테나는 타이어 센서부에 장착되고, 타이어 휠(wheel)에 고정되어야 하는 구조적 특성이 있다. 이는 송신 안테나의 설계에 있어 구조적 크기 를 소형화하고 휠로 인한 방사 전력의 감쇄를 최소 화하는 데 역점을 두고 설계해야 함을 의미한다. 이 러한 관점에서 본 논문에서는 타이어 휠의 그라운드 면과 수직 방향으로 안테나를 설계하여 방사 효율이 증가될 수 있도록 설계하였다.

아울러 압력 센서부가 타이어의 내부에 장착되어 야 하는 공간적인 제한(센서 보드: $30 \mathrm{~mm}(W) \times 47$ $\mathrm{mm}(D) \times 10 \mathrm{~mm}(H))$ 이 있음을 감안하여 물리적인 크 기를 최소화하였다. 또한, $433 \mathrm{MHz}$ 주파수 공진을 위하여 스파이럴(spiral) 구조로 설계하였다. 그림 1 은 이러한 개념을 바탕으로 안테나 시뮬레이션 프로 그램인 CST를 활용하여 설계한 모습을 보여주고 있다.

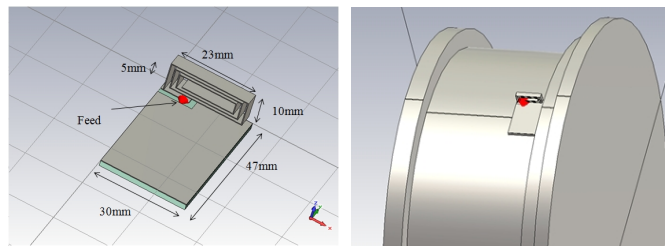

그림 1. 송신 안테나의 설계 및 파라미터

Fig. 1. Transmit antenna design and parameter.

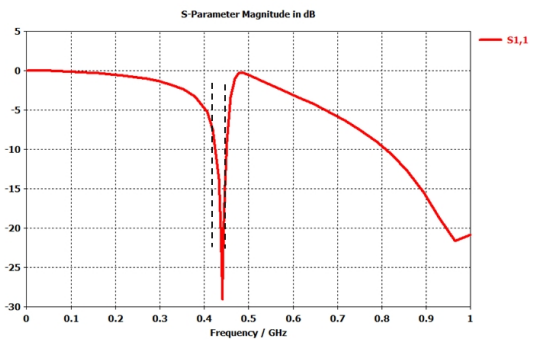

그림 2. 설계된 안테나의 $S_{11}$ 시뮬레이션 결과

Fig. 2. $S_{11}$ simulation results of designed antenna.

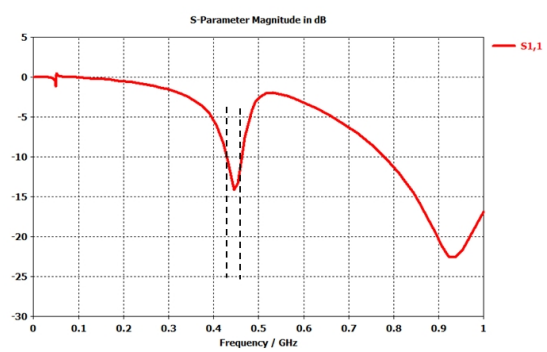

그림 3. Wheel 장착 후 $S_{11}$ 시뮬레이션 결과

Fig. 3. $S_{11}$ simulation results of mounted on wheel.
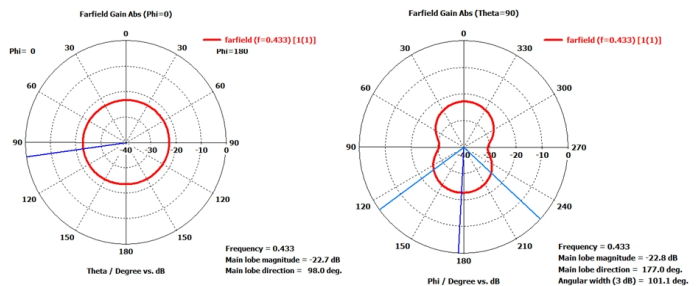

그림 4. 설계된 안테나의 방사 패턴

Fig. 4. Radiation pattern of designed antenna.

설계는 안테나를 $50 \Omega$ 임피던스에 매칭시키고 $433 \mathrm{MHz}$ 주파수에 공진이 되도록 길이, 높이, 폭 및 스파이럴 턴수를 조정하면서 최적화시켰다. 그림 2, 4는 위의 조건에 따라 설계된 안테나의 반사 손실 $\left(S_{11}\right)$ 과 방사 패턴을 보여주고 있는데, $-10 \mathrm{~dB}$ 대역 


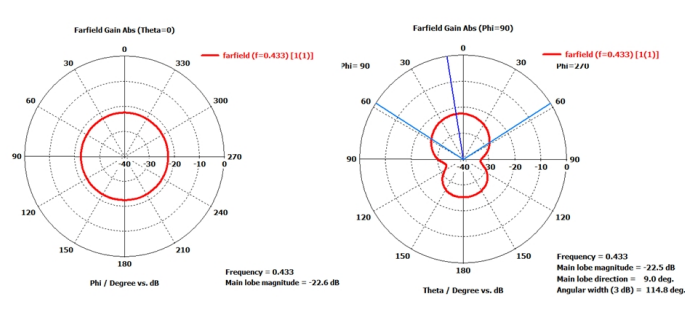

그림 5. Wheel 장착 후 안테나의 방사 패턴

Fig. 5. Radiation pattern of mounted on wheel.

폭이 $23 \mathrm{MHz}(427 \sim 450 \mathrm{MHz})$ 를 확보하고 있음을 확 인할 수 있으며, Wheel에 적용 시에도 반사 손실(그 림 3)과 방사 특성(그림 5) 모두 크게 변하지 않는다 는 것을 확인할 수 있다. 이는 국내 TPMS의 기술 기 준이 중심 주파수 $433.92 \mathrm{MHz}$, 대역폭 $250 \mathrm{kHz}$ 임을 감안할 때 설계된 안테나가 충분한 대역폭의 확보가 가능함을 보여주는 결과이다.

\section{III. 안테나 제작 및 측정}

시뮬레이션 결과를 기초로 두께가 $0.3 \mathrm{~mm}$ 인 황동 재질로 $5 \mathrm{~mm}(W) \times 23 \mathrm{~mm}(D) \times 10 \mathrm{~mm}(H)$ 로 그림 6과 같이 제작하였다. 또한, 스파이럴 구조로 인한 단락 을 방지하기 위해 열 수축 튜브를 사용하였다.

제작된 안테나의 특성을 분석하기 위하여 먼저 네트워크 분석기로 반사 손실을 측정하였다. 송신 안테나를 휠에 부착한 후 반사 손실은 $433 \mathrm{MHz} \pm 10$ $\mathrm{MHz}$ 대역에서 $-10 \mathrm{~dB}$ 이하의 값을 보였으며, 이는 충분한 대역폭의 확보가 가능함을 보여주는 결과이 다. 그림 7,8 은 제작된 안테나를 타이어 휠에 부착 한 모습과 반사 손실을 측정한 사진을 보이고 있다.

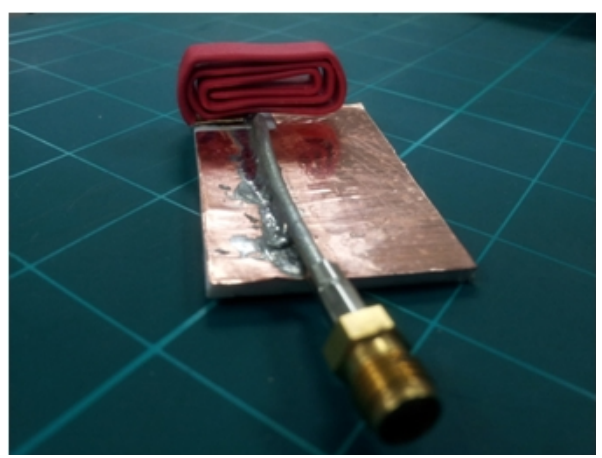

그림 6. 제작된 안테나(프로토타입) 모습

Fig. 6. Figure of fabricated prototype antenna.

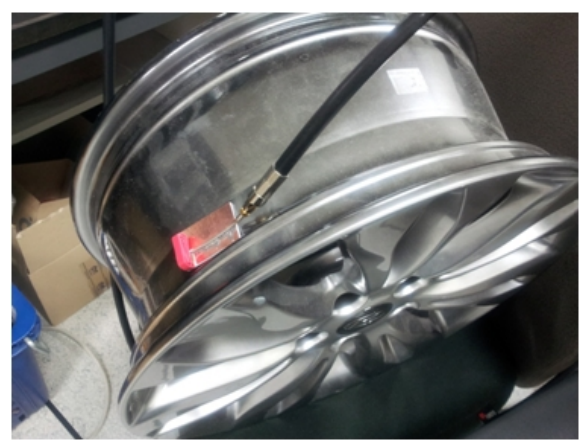

그림 7. 휠에 부착된 안테나의 모습

Fig. 7. Figure of mounted antenna on wheel.

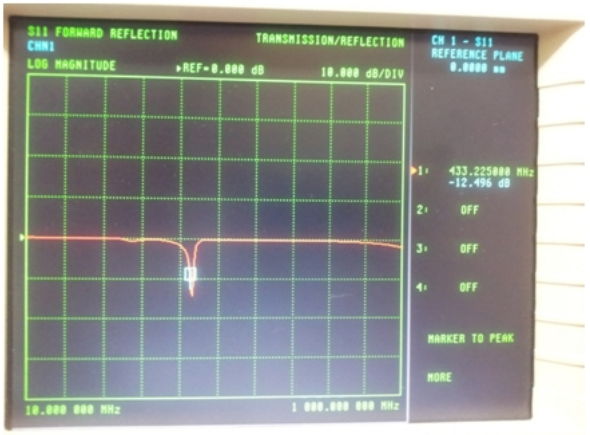

그림 8. 휠에 부착된 상태에서의 $S_{11}$ 측정값

Fig. 8. Figure of measured $S_{11}$ of mounted on wheel.

다음으로 제작된 안테나를 실제 차량의 휠 및 타 이어에 장착하고, 차량의 내부에서 수신이 가능한지 를 측정하였다. 그림 9는 제작된 안테나를 휠 및 타 이어에 장착한 모습과 약 $0.7 \mathrm{~m}$ 거리에서 위치한 수 신 안테나에서의 수신 전력을 측정하는 실험 모습을 보여주고 있다.

안테나의 방사 전력은 휠 및 타이어 장착전 -44.21 $\mathrm{dBm}$ 으로 측정되었으며, 타이어 및 휠에 장착한 후 에는 $-50.0 \mathrm{dBm}$ 으로 측정되었다. 이는 휠 및 타이 어 철심으로 인하여 $5.8 \mathrm{~dB}$ 의 손실이 발생한 것으로 보인다. 이후 실제 차량(기아자동차, 로체)의 4 개 바 퀴에 타이어를 장착한 후 차량의 내부에 수신 안테 나를 설치하고 측정하였는데(그림 10$)$, 이 경우 -63.5 $\sim-69.5 \mathrm{dBm}$ 의 값을 보였다(표 1). 타이어를 차량에 설치한 후 차량 내부에서 측정한 결과, 약 13.5 19.5 $\mathrm{dB}$ 의 감쇄가 일어났는데, 이는 철판으로 구성된 차 량의 도어 등으로 인한 감쇄로 예상된다. 그러나 압 력 센서의 데이터를 수신할 수 있는 최저 수신 레벨 

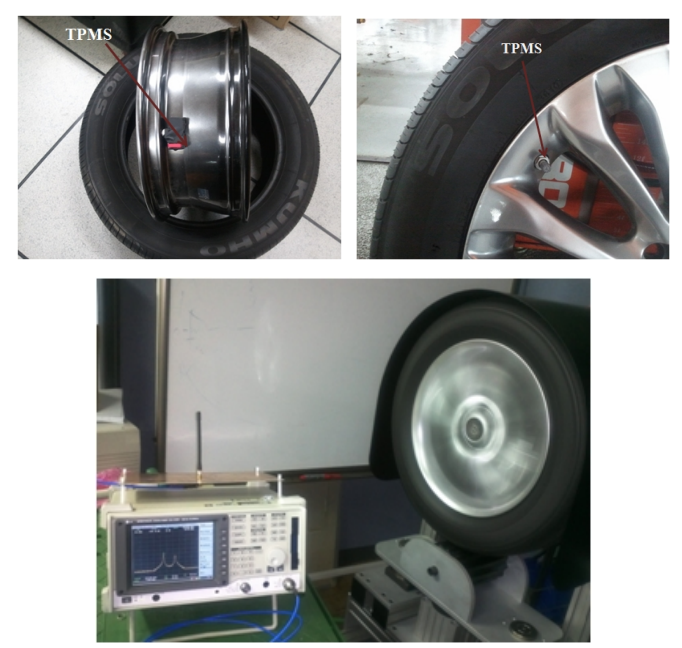

그림 9. 타이어 장착 후 방사 전력 측정 모습

Fig. 9. Figure of measuring radiation power after installed tire.

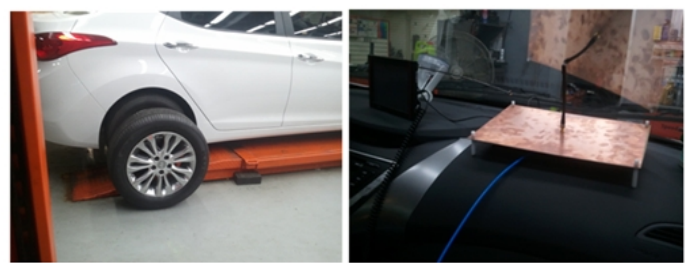

그림 10. 차량에 적용 후 방사 전력 측정 모습

Fig. 10. Figure of measuring radiation power after installed car.

표 1. 제작된 안테나의 방사 전력 비교

Table 1. Comparison of radiation power in fabricated antenna.

\begin{tabular}{|c|c|c|}
\hline 구 분 & 방사 전력( dBm) & 비 고 \\
\hline 휠 미부착 시 & -44.21 & \multirow[b]{2}{*}{$\begin{array}{l}\text { 송신 출력: } \\
\text { 약 }-2 \mathrm{dBm}\end{array}$} \\
\hline $\begin{array}{l}\text { 휠 및 타이어 } \\
\text { 장착 후 }\end{array}$ & -50.0 & \\
\hline $\begin{array}{c}\text { 차량 내부에서 } \\
\text { 측정값 }\end{array}$ & $\begin{array}{c}\text { 오른쪽 앞바퀴: }-64.38 \\
\text { 왼쪽 앞바퀴: }-63.55 \\
\text { 오른쪽 뒷바퀴: }-69.50 \\
\text { 왼쪽 뒷바퀴: }-68.16\end{array}$ & $\begin{array}{l}\text { 최저 요구 } \\
\text { 방사 전력: } \\
-92.0 \mathrm{dBm}\end{array}$ \\
\hline
\end{tabular}

이 $-92 \mathrm{dBm}$ 임을 감안할 때, 제작된 송신 안테나의 방사 전력 값은 이보다 큰 값을 보이고 있어 데이터 수신에는 문제가 없음을 확인할 수 있었다.

\section{IV. 결 론}

본 논문에서는 직각 스파이럴 형태의 TPMS용 송 신 안테나를 설계·제작하였다. 설계된 안테나의 $433 \mathrm{MHz}$ 주파수에서 $-10 \mathrm{~dB}$ 반사 손실은 $23 \mathrm{MHz}$ $(427 \sim 50 \mathrm{MHz})$ 가 확보되었다. 설계값을 기초로 5 $\mathrm{mm}(W) \times 23 \mathrm{~mm}(D) \times 10 \mathrm{~mm}(H)$ 의 크기로 안테나를 제 작하였다. 타이어 장착 전후의 방사 전력을 측정한 결과, 각각 $-44.21 \mathrm{dBm}$ 과 $-50.0 \mathrm{dBm}$ 으로 약 5.8 $\mathrm{dB}$ 의 감쇄가 일어났으며, 안테나를 부착한 타이어를 실제 차량의 휠에 장착한 후 차량의 내부에서 측정 시 약 13.5 19.5 dB의 감쇄가 일어남을 확인하였다. 이는 차량의 철판에 의한 감쇄로 보이나, 압력 센서 데이터의 수신 가능 최저 방사 전력인 $-92 \mathrm{dBm}$ 보 다 큰 값을 보이고 있어 송신 안테나로 적용 가능함 을 확인할 수 있었다.

\section{참 고 문 헌}

[1] US Dep. of Trans and National Highway Traffic Safety Admin., An Evaluation of Existing Tire Pressure Monitoring Systems, 2001.

[2] H. J. Song, T. Talty, "Modeling signal strength range of TPMS in automobiles", Proc. of IEEE Ant. and Prop. Society International Symposium, vol. 3, pp. 3167-3170, Jun. 2004.

[3] K. Tanoshita, K. Nakatani, and Y. Yamada, "Electric field simulations around a car of the tire pressure monitoring system", IEICE Trans. Commun., vol. E90-B, no. 9, Sep. 2007.

[4] A. Ozdemirli, M. M. Bilgic, and K. Yegin, TPMS Receive Antenna Design for Large Vehicles, IEEE Conference Publication, pp. 1-4, 2011.

[5] Shanhong He, Jidong Xie, "A novel compact printed antenna used in TPMS or other complex and variable environments", IEEE Journals \& Magazines, pp. 24-30, Jan. 2008.

[6] B. H. Sun, Q. Zh. Liu, "Polarisation-diversity antenna for TPMS application", IET Journals \& Magazines, vol. 43, pp. 603-605, May 2007. 